\title{
CHILDREN AND VIOLENCE
}

THE CHALLENGE TO GUARANTEE THE RIGHTS IN THE CHILDREN'S DAILY CONTEXTS

Executive Summary of the 2018 Investigation Report

Ana Maria Eyng 
This study results from the Cooperation Agreement between the Inter-American Children's Institute (IIN), the Organization of American States (OEA), the Marist International Solidarity Foundation (FMSI), the Pontifical Catholic University of Paraná (PUCPR), of the Paranaense Association of Culture (APC).

\section{TECHNICAL TEAM}

Inter-American Children's Institute (IIN) Organization of American States (OEA) Víctor Giorgi - General Director of IIN Daniel Claverie - Consultant in the field of Promotion and Protection of the Rights of IIN

Marist International Solidarity Foundation (FMSI)

Anália Ruggeri - Coordinator of the Regional Office of the FMSI (Cono Sur)

Álvaro Danilo Sepúlveda Romero - Office of Defense of the Rights of the Child of FMSI Bárbara Pimpão Ferreira - Manager of the Marist Center of Defense of Children of the Marist Solidarity Network.

Pontifical Catholic University of Paraná (PUCPR) Paranaense Association of Culture (APC) Délcio Afonso Balestrin - President of APC Waldemiro Gremski - Rector of the PUCPR Fabiano Incerti - PUCPR Observatory of the Youth Ana Maria Eyng - Program for Master and Doctorate in Education (PPGE/PUCPR)

Research

Ana Maria Eyng (Coordinator)

Group of Investigation: Public Policies and Teacher Training - Program for Master and Doctorate in Education (PPGE/PUCPR) Participation in the activities of data collection in Brazil, digitalization and digital recording of Interviews in Mexico, Guatemala, Chile.

\section{Ana Maria Eyng}

Ana Paula Feuser Eyng

Angela Negrete Adriàzola

Auda Aparecida Ramos

Bruna de Oliveira Silva Mosson

Eduardo Felipe Hennerich

Janice Strivieri Souza Moreira

Jéssica Adriane Pianezzola

José Luis de Oliveira

Laís Rolim Simão

Marciele Stigler Ribas

Marilene Duarte

Marina Ignez de Oliveira

Mônica Luiza Simião Pinto

Ricardo Lemes da Rosa

\section{Collaborators}

Arturo Latorre Tarragó

Jesús Balmaseda Aragón

Maria del Socorro Alvareza Noriega

Maria Victoria Racancoj Mejía

Monica Gabriela Yerena Suárez

PUCPRESS/Champagnat University Publishing House

Coordinator: Michele Marcos de Oliveira

Editor: Susan Cristine Trevisani dos Reis

Art editor: Rafael Matta Carnasciali

Text preparation: Paula Lorena Silva Melo

Proofreading: Susan Cristine Trevisani dos Reis

Cover and graphic design: Rafael Matta Carnasciali

Layout: Rafael Matta Carnasciali 


\section{SUMMARY}

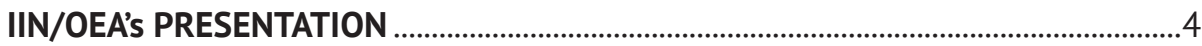

Víctor Giorgi

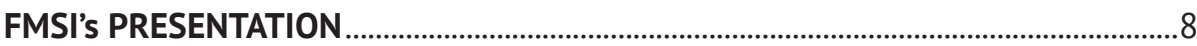

Álvaro Sepúlveda Romero

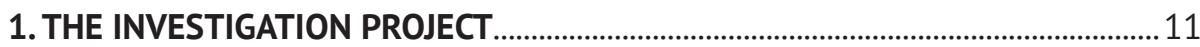

Ana Maria Eyng

2. VIOLENCE-GENERATOR STRUCTURAL FACTORS IN

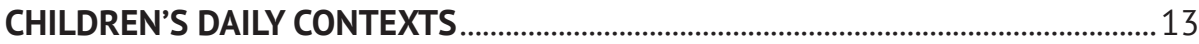

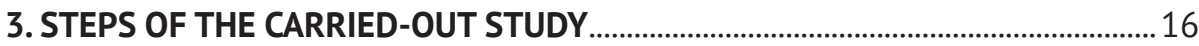

4. ORGANIZATION AND HIGHLIGHTED ELEMENTS OF THE REPORT .....................19

4.1 VIOLENCE RISK FACTORS IN THE DAILY LIFE OF CHILDREN......................20

4.2 CHARACTERIZATION OF THE CONSULTED SUBJECTS.................................... 22

4.3 PARTICIPATION AND DYNAMICS IN THE PROGRAMS..................................... 24

4.4 RIGHTS AND THEIR GUARANTEE IN THE PROGRAMS .....................................26

4.5 LEARNING CONSTRUCTED IN THE PROGRAMS ............................................ 27

4.6 FACTORS OF PROTECTION IN CHILDREN'S DAILY CONTEXTS .................... 30

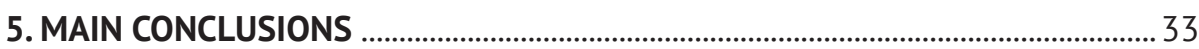

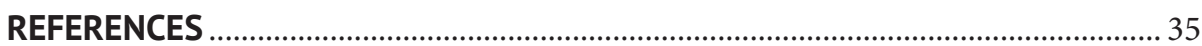




\section{IIN/OEA's' ${ }^{1}$ PRESENTATION}

\section{Victor Giorgi ${ }^{2}$}

This publication contains the final report of an investigation and research process that aims to construct knowledge beginning by the analysis of programs developed in the state orbit and in civil society, in different countries of the American Region.

It takes as a starting point the process of construction of knowledge, the practices that different institutional actors have been developing to try to promote, protect and give back the rights of girls, boys and adolescents in daily spaces. This knowledge aspires to go back on practice in the form of instruments, models of intervention and strategies that will strengthen the collective capacities to transform the conditions of children and adolescents' lives.

In the institutional plan, the study is the product of an alliance between an interstate international organism specialized in children and adolescents, an organization of the civil society present in several countries of the American Region and a research team from the Academy. This way, a proposal of joint work becomes concrete, strengthening resources and efforts in favor of generating useful knowledge to advance toward the eradication of violence against children and adolescents in all its forms and in all fields, such as stated by the United Nations among the Sustainable Development Goals (SDGs).

Another strength of the study's methodology is the central place that it gives to the word of those who from different places lead these experiences. It listened to boys, girls and adolescents, as well as to fathers, mothers, grandmothers, professionals and operators, gathering their perceptions and

\footnotetext{
Organization of American States (OEA), that contains the Inter-American Children's Institute (IIN).

${ }^{2}$ General director IIN/OEA, e-mail: direcciongral@iinoea.org.
} 
opinions on the theme and on the contribution that these programs make for the transformation of their life conditions.

Beginning with the information gathered, risk and protection factors are identified in different fields; family, community, social policies, financial aspects, such as quality of employment, and lack of opportunities, to overcome poverty; access to education, a culture that naturalizes violence between gender and generations, discrimination and stigmatization of children, high consumption of drugs, depression, low self-esteem, insecurity in contexts of criminality, conceived as a protection and subsistence factor. To this is added the scarcity or lack of opportunities for the development of children in all different cycles of life.

The findings contribute with new empirical evidences that reaffirm the need to understand violence from a systematic and ecological model that includes micro and macro-social, economic, linking and cultural factors, in permanent interaction and retroaction.

Violence is not a problem simply reduced to behavior of individuals when considered in isolated form, nor of families impregnated with pathological factors. In proposing ourselves to eradicate all forms of violence toward children, we must take into account that structural factors exist, and that associated to them we find the cultural constructions regarding children which legitimize the use of violent methods as a form of exercising the power of adults.

Disciplinary methods based on violence, in punishment in its different forms, are an ancestral tradition, which starts from a paradigm that defines the boy or girl like a being to be domesticated, tamed. The social mandate that devolves on the adults is that of using discipline at all costs. This way of looking at them does not recognize them as persons capable of having their own opinions and of having a dialogue with adults.

At almost three decades after the approbation of the Convention on the Rights of the Child by the United Nations, much has advanced on different levels, but cultural transformations related to the social representations of children continue to be anchored on adult-centric conceptions, which devalue and stigmatize boys, girls and adolescents, especially those that have the condition of poverty added to their children character. 
The systematic exercise of violence as a royal way in the resolution of conflicts leads to the functioning of a feedback circuit, which includes violence of little visibility and other greatly spectacular. Among the first ones, socially accepted or at least minimized regarding their effects, we find punishment in the family environment, discrimination, symbolical violence, which boys and girls suffer in both family, institutional and community environments. Other more spectacular violence, such as actions of organized crime or criminal acts adjudicated to adolescents, motivate press headlines and invade political agendas delivering discourses based on security.

There is evidence that people who have suffered or have been present and witnessed intra-family violence during their childhood are at greater risk of becoming victims or victimizers of expressions of criminal violence in their adult age. From here follows the strategic importance that the elimination of all violence has, in the process of constructing a culture of rights.

To put an end to ill-treatment, exploitation, traffic and all forms of violence and torture against children, defined as a SDG goal (Goal 16.2) requires policies that will impact on the causes, that act in preventing the violation of integrally conceived rights, that will promote a new form of perceiving and valuing children, assuming their protection as a priority and collective responsibility and creating favorable environments for their development from the beginning of their lives.

From the IIN we completely subscribe the conclusion of this study.

The strengthening of every child and their acknowledgement as subject of RIGHTS requires the deconstruction of concepts and practices already very internalized in the daily spaces of boys and girls. Therefore, it implies unlearning violence, discrimination, lack of respect, the assistance, - a political attitude directed to solve problems by means of external help instead of generating structural solutions - the blaming of the victim, the subordination and disqualifying the child. Moreover, consequently, it implies learning new individual and collective strategies, which will allow 
every child to go back to their life projects to attain a less unjust present and a future with greater equity.

To end, from IIN/OEA, we express our most firm desires that this study constitutes a contribution, which will strengthen the capacities of the States, Civil Society Organizations and societies as a whole, to advance toward democratic forms of lived experience, which will recognize and include children and adolescents as full citizens, and prepare spaces of expression and intergenerational dialogue ${ }^{3}$.

Víctor Giorgi

General Director - IIN/OEA

${ }^{3}$ Extract of the text withdrawn from the Final Report (in press). 


\section{FMSI's ${ }^{4}$ PRESENTATION}

\section{Álvaro Sepúlveda Romero ${ }^{5}$}

The Marist International Solidarity Foundation (FMSI) was founded in the year 2007 with the objective of making of the world a better place for the boys, girls and adolescents who grow up in socially vulnerable contexts. It is inspired in the person of Saint Marcellin Champagnat and promoted by the Marist Brothers of the Schools, a Catholic religious Congregation present in 80 countries of the world.

FMSI has more than ten years of experience, working in the field of solidarity, supporting the promotion and defense of the rights of boys, girls and adolescents. It seeks to promote an innovating way of thinking, as well as practical initiatives supporting spaces of political impact or effect and granting support to local experiences. It was officially constituted in Italy in 2007 as a "Non-Profit Organization for Social Benefit". Since the year 2011, it has the consultative status by the Council of Economic and Social Rights of the United Nations. The Representation Office in Geneva (Switzerland), the See of the Human Rights Council, gives the FMSI the opportunity to participate in important conferences of the UN, encounters and working groups on the rights of children.

FMSI supports educational and social assistance projects in developing regions of the world, which benefit children and young people, especially those in greater need and who are forgotten. We establish relations with foundations, agencies and individual donors to support the work of our Marist collaborators. We help them to prepare and draw up, solicit and present reports on projects, which have been financed by our donors.

\footnotetext{
4 Marist International Solidarity Foundation (FMSI), which integrates the Marist Institute.

5 Official of Defense of the Rights of Children, e-mail: asepulveda@fms.it.
} 
We are aware that when many voices express themselves in unison, the probability of carrying out effective changes in society and of being listened by those who can exercise influence in the changes is greater. Therefore, FMSI works with other NGOs, networks, coalitions and groups, which share our objectives and values.

After 200 years of history of the Marist Institute and 130 of presence in 21 countries of the American continent, we Marists feel responsible for contributing our voice, experience and resources to bring about the transformation of the structures, which provoke several infringements of rights.

Considering this challenge, in September 2013, the Cono Sur Office of FMSI was constituted, with the objective of coordinating strategies to promote and defend the rights of children, sharing learning and resources, to strengthen the presence of FMSI in the region, profiting from our access to financing and our presence in the United Nations.

Together with the other coalitions, reports have been prepared and presented for the Universal Periodical Examination of Peru, Bolivia, Chile, Paraguay, Argentina, Brazil, Guatemala, Nicaragua, Mexico, Costa Rica and Uruguay. For monitoring the rights based on statistic data, in 2012 it was created the Children and Adolescents Observatory of Chile. Progressively, we have added ourselves to national platforms and in 2014 we incorporated ourselves to the greatest coalition for the rights of children existent in the continent, the World Movement for Children in Latin America and the Caribbean. From there we have favored the participation of the children in the discussion on the Sustainable Development Goals (2030 Agenda), in the struggle for the elimination of physical and humiliating punishment in the region, among other initiatives.

In collaboration with $\mathrm{BICE}^{6}$ (International Catholic Office of Children) the creation of national committees was impelled or promoted in Chile, Brazil, Argentina and Guatemala. This has been a privileged space to support common challenges together with Church Organisms, which want to promote the human rights agenda.

${ }^{6}$ Bureau International Catholique de l'Enfance. 
In 2016, FMSI Cono Sur signed an agreement of collaboration with the Inter-American Children's Institute (IIN). In this framework, it was decided to carry out an investigation on experiences on the eradication of violence against children of America, together with the Pontifical Catholic University of Paraná.

The theme of violence is a key point for the Marist Institute from its origin. The foundational intuition arises from the impact that corporal punishment created in a child, exercised by a professor of a rural school in France at the beginning of the 19th century. This child, Marcellin Champagnat, understood that the children of the country should receive an education based on respect and love, and he dedicated his whole life to this. Up to the time of his death, he inculcated in the Marist educators the importance of eradicating physical and psychological ill-treatment from the schools.

For this reason, we support the recommendations of the Study of the United Nations on violence against children (2006), especially regarding its invitation to forbid every type of violence toward children, in all environments, including corporal punishment. We also agree with the need to promote the reflection and commitment with non-violent values, to transform those attitudes which naturalize violence, especially in the education and discipline guidelines, by adults.

The new sensitiveness in this field and the ethical standards, more demanding from day to day, require the development of initiatives that promote non-violent forms in education, where discipline can be transformed into an authentic pedagogy of autonomy. It requires to favor sane links between parents and children and to orientate toward constructive and positive criteria for the development and growth of boys, girls and adolescents.

\author{
Álvaro Sepúlveda Romero \\ Official of Defense of the Rights of \\ Children Marist International Solidarity Foundation
}




\section{THE INVESTIGATION PROJECT}

\section{Ana Maria Eyng ${ }^{7}$}

Este documento presenta una visión general del estudio desarrollado en el This document presents a general vision of the study developed in the framework of the cooperation agreement between the Inter-American Children's Institute (IIN), which integrates the Organization of American States (OEA), the Marist International Solidarity Foundation (FMSI), the Paranaense Association of Culture (APC) and the Pontifical Catholic University of Paraná (PUCPR).

The study is the fruit of the inter-institutional collaboration for the strengthening of policies and programs that effectively guarantee the rights of girls, boys and adolescents. At the end of the second semester, 2016, a cooperation agreement was signed between the Inter-American Children's Institute (IIN), which belongs to the Organization of American States (OEA), represented by its General Director, Mr. Víctor Giorgi; the Marist International Solidarity Foundation (FMSI), represented by Mrs. Analia Ruggeri; and the Paranaense Association of Culture (APC), represented by its President Délcio Afonso Balestrin, maintainer of the Pontifical Catholic University of Paraná (PUCPR), represented by its Rector Waldemiro Gremski.

The cooperation agreement was motivated by the need of uniting efforts to carry out a regional study in the ambit of the Americas, in order to identify, systematize, and analyze important experiences for the prevention and eradication of violence in the daily lives of girls, boys and adolescents.

In the execution of the Cooperation Agreement it was FMSI's responsibility, through Álvaro Sepúlveda of the Office of the Defense of the

7 Full Professor and Investigator of the Program for Master and Doctorate in Education (PPGE/ PUCPR). Post-Graduate in Human and Social Sciences in the area of Studies of Minorities, e-mail: ana.eyng@pucpr.br. 
Rights of the Child in Rome, in association with PUCPR, the appointment of an investigator for the development of the study, through the Director of the PUCPR Observatory of the Youth, Dr. Fabiano Incerti. FMSI appointed teacher Bárbara Pimpão Ferreira, Manager of the Marist Center of Defense with its see in Curitiba (Paraná, Brazil), as the contact for the execution of the operational agreement. To IIN it was given the responsibility for the management among the States of the Region to obtain the necessary information to carry out the study, through Professor Daniel Claverie, consultant in the Area of Promotion and Protection of Rights at IIN/OEA.

For the carrying out of the investigation project it was appointed Dr. Ana Maria Eyng, professor and investigator of the Post-Graduate Program of Master and Doctorate in Education from the Pontifical Catholic University of Paraná (PPGE/PUCPR). As her first activity, the investigator presented to IIN a proposal for a working plan for the project, called "Guarantee of the rights in the daily contexts of boys, girls and adolescents: contributions of programs developed in the state orbit and in civil society in the international sphere".

All the coordination and notification process of the investigation's operational agreement was constructed in association. The group's participants were: Álvaro Sepúlveda Romero (FMSI, Daniel Claverie (IIN/OAE), Fabiano Incerti (PUCPR), Bárbara Pimpão Ferreira (FMSI) and Ana Maria Eyng (PUCPR). They kept a work agenda for constant accompaniment during the development of the study.

The study culminated in the systematization of the experiences identified in all three Regions of America (North, Central, South), including programs developed in the state orbit and in civil society. The final products of the agreement are presented in three documents, in the format of: a general report with the details of the resulting data, a presentation video and this executive summary.

From the report on the study, we emphasize in this summary the structural factors of this scene in which violence is general, justified and maintained in the daily contexts in which, boys, girls and adolescents grow. The information we got from the study allows us to situate the study considering its itinerary and the obtained results - in perspective to 
overcome the difficulties, favor benefits, make viable learning that is capable of acting as resources of protection and guarantee of rights in the face of violence.

The detailed data is available in the general report to be published. Have a good reading!

Keywords: Public policies. Human rights. Violence in the daily context of girls, boys and adolescents. Guarantee of the rights of children and adolescents.

\section{VIOLENCE-GENERATOR STRUCTURALFACTORS IN CHILDREN'S DAILY CONTEXTS}

The world scene of children is strongly marked by violence, especially in those contexts characterized by poverty and extreme poverty. This affects the development in the daily life of children, whose lives are marked by inequality, exclusion, lack of goods and of services, and of the most fundamental conditions of security and survival. The more basic rights, precariously guaranteed and frequently violated, affect even the proper right to life. This is very evident by the large number of deaths in the first years of life.

In these contexts, the principal and perverse lessons that daily life teaches boys and girls is lack of trust, frustration, undervalue or low selfesteem, due to the privations, ill-treatment, abandonment, and sexual abuse, physical, psychic and emotional violence to which they are exposed.

Structural factors (economic, political, social and cultural) are in the genesis of violence. They act as pillars that support the various phases of infringement of the human rights and, especially, of the rights of children. These factors are strengthened in cultural and epistemological discourses which legitimize them, and in political strategies of pacifying or restraining the excluded.

In this scenario, indicative of factors that generate and perpetuate violence are inequality, the compensating policies, the colonial epistemology, the projection of the identity of the offender, the poverty of children. All these factors are related and strengthen each other, exposing boys and girls to 
significant risks of violence. The greater the combination of risk factors that act on children, the greater the harm suffered by boys, girls and adolescents.

Inequality and, therefore, social exclusions manifest themselves in the extreme imbalance observed in the economic, cultural, political and symbolical plan, producing and perpetuating the dynamics of violence. In the meantime, social and institutionally constructed phenomena, inequality and violence, derived from there, are learnt; therefore, they need to be unlearned, since it is believed that they can be deconstructed.

The compensatory policies, which are focused on the effects of violence, only obtain to maintain it and increase it since they are based on social security or welfare and express themselves in concrete actions, which strengthen their presence and the immediacy. In becoming concrete actions, those policies touch only a part of the symptoms, acting on the consequences without foreseeing or treating the causes.

This scenario becomes worse in function of the colonial epistemologies that justify, strengthen and maintain violence. These are valued as suppositions of hegemonic standardization and impose the subordination of narratives, characteristics and individual features, which are different from the ruling norm. In this way are produced, justified and perpetuated male chauvinistic and adult-centric discourses and practices, which oppress and hurt the children.

Among the effects of the structural violence is the projection of the offender identity, of the periphery, which is produced by the stigmatization of poverty. A difference, which has repercussion in the constitution of the ' $T$ ', is stressed generating low self-esteem, a fragile self-love. It is a dynamic that justifies, strengthens and maintains violence while the victim then goes on to recognize oneself as responsible and assumes the fault of their condition.

In the situation of the production of poverty, this is of even greater concern when it affects boys, girls and justifies, strengthens, and maintains the dynamics of violence, producing the phenomenon of children's poverty. The precariousness of the life conditions of children intensifies their vulnerability, generating abandonment, ill-treatment, abuses, situations of exploitation on the part of adults, caretakers and institutions. At the same time, it has repercussions in failure, and school abandonment. 
Poverty as an ontological category acts, morally and socially, as a disqualifier, models the stigma of poverty, going on to naturalize it and to understand it as part of the essence of "being poor". It dissociates, therefore, poverty from structural conditions that produce it and maintains the subjects in the state of poverty and inequality. It is necessary to distinguish between the state, "being poor", generated by the structural conditions which provoke privations, from the supposed essence of "being poor".

"Poverty does not form part of the essence of determinate groups of persons, even though it may be common that there is attributed to the poor (...) a series of disqualifying characteristics, in the moral and social plan" (SARMENTO, 2010, p. 181). Evidently, those ideological stigmatizing processes affect the poor boys and girls. In this way, it takes place "[...] an operation of accusation of the victims, the effect of which is the legitimization of social inequalities, the effects of which are profoundly harmful for the one who suffers the stigma associated to poverty" (SARMENTO, 2010, p. 182). This is a repercussion of the labeling of poverty.

The compensation policies and the actions of assistance destined for children may also be understood as anchored on labels attributed to poor children. Sarmento (2010) describes the effect of a triple ideological association: the ontologicalization of poverty, the fatalist vision of the social condition and the pious attitude.

The consequences of the first of these factors, ontologicalization of poverty, causes poor boys and girls to be seen as "[...] poor by nature and not like a human being of young age who finds oneself in a precarious social condition (then constructed artificially, eventually temporary and transformable)" (SARMENTO, 2010, p. 182). The second effect, the fatalist vision of the social condition causes poor boys and girls to be seen and treated as "[...] the 'poor little one' a victim of destiny, and not the human being who finds oneself in a situation of privation by the effect of other human beings' action" (SARMENTO, 2010, p. 182). The third effect, the pious attitude "[...] is reproduced in the charitable behavior, potentially pacifying of individual consciences or in the welfare intervention, not structuring of new social conditions of existence" (SARMENTO, 2010, p. 182). 
Therefore, guided by this logic, the policies and programs will act in the maintenance and reproduction of the cycle of poverty, which means to maintain and strengthen the factors of risk of current violence in the daily life of children. On the contrary, the role of the policies and programs destined to children has the fundamental proposal to protect and guarantee their rights to integral development.

\section{STEPS OF THE CARRIED-OUT STUDY}

The study on the guarantee of rights in the daily contexts of boys, girls and adolescents, with emphasis on the contribution of programs developed in the state orbit and in civil society, was carried out in three phases: planning, field study and systematization.

The first phase of the Project's planning began in the second semester of 2016, when a first draft was presented for the study. It was returned in March 2017 with the definition of the selection criteria and inclusion of the countries, programs and subjects, as well as the construction and validation of the instruments. Later, the project was submitted to ethical evaluation ${ }^{8}$.

The second phase included the collection of field data, begun in Brazil in the month of June. In September, the investigation was carried out in Mexico, at the end of September and first fifteen days of October in Guatemala, and finally, in November it was applied in Chile.

In this phase, empirical data was gathered in six different programs, among which three were considered in Brazil, one in Mexico, one in Guatemala and one in Chile:

\footnotetext{
${ }^{8}$ The ethical evaluation was carried out via platform Brazil, under the number 65770517.6.0000.0020, to obtain the Certificate of Presentation for Ethical Appreciation (CAAE). The Project was approved by the ethical committee which gave its opinion on April 5, 2017, under the number 2002.093. The following considerations and conclusions were presented: "the project of investigation presents a methodology in harmony with the objectives; all the terms were adequately presented; the project of investigation takes care of the ethical requirements of the Resolution CNS n 466 of 2012 of the CEP/CONEP system".
} 
- Marist living together: confessional organization of civil society located in the city of Sao Paolo, Brazil.

- Specialized Program in Socio-educational Measures in open means (PEMSE): it is a public program dependent on the Municipal Secretariat of the Municipality of Colombo in the State of Paraná, Brazil.

- Allow the Child to Play (DMJ): it is a mixed program, a publicprivate association between the Municipal Secretariat of Sports and Leisure (SEMEL) and the organization of the civil society "Allow the Child to Play". It is carried out in the city of Sao Jose dos Pinhais (Paraná, Brazil).

- Reintegrate, of the Mexican Foundation of Social reintegration: it is a non-profit organization of the civil society in the City of Mexico.

- Association La Alianza (ALA): it is a non-profit association of the civil society. It is in the city of Guatemala.

- Respite - Marist Community Program: initiative of civil society impelled by the Marist Foundation of Solidarity (GESTA) in the Municipality of Pintana, Metropolitan Region of Santiago, Chile.

In the investigation participated: 295 subjects, distributed in three groups: 126 boys, girls and adolescents (10 to 18 years of age); 92 mothers, fathers, grandparents and legal representatives whom we name "relatives" and 77 managers, educators, professional operators of the programs, called "team".

Table 1 - Sample - Subjects by programs in the four countries

\begin{tabular}{lcccc}
\hline Países / Programas & NNA & Familiares & Equipo & Total \\
\hline Brazil - Living together & 30 & 15 & 10 & 55 \\
\hline Brazil - PEMSE & 13 & 14 & 09 & 36 \\
\hline Brazil - DMJ & 16 & 16 & 04 & 36 \\
\hline Mexico - Reintegrate & 21 & 19 & 17 & 57 \\
\hline Guatemala - ALA & 24 & 13 & 22 & 59 \\
\hline Chile - Respite & 22 & 15 & 15 & 52 \\
\hline TOTAL & 126 & 92 & 77 & 295 \\
\hline
\end{tabular}

Source: Investigation - Guarantee of rights of Children/IIN/OEA/FMSI/PUCPR Agreement 2017-2018. 
The third phase was the work of systematization and analysis of the elements identified in the experiences, obtained in the two previous phases. The systematization of data included the digitalization and digitation of responses to interviews, as well as the transcription of approximately 120 hours of audios of interviews in the field. In that phase, the data of the open questions were individually analyzed, categorized, and systematized by the responsible investigator, originating 40 tables and 59 charts, which are presented in the complete report of the investigation with the title: "Guarantee of rights in the daily life of boys, girls and adolescents: contributions of programs developed in the state orbit and in civil society in the international field".

The information collected in the six programs mentioned before nourished the formularies developed to insert the data in the software Sphinx Lexica. The 289 graphs presented in the complete report are the product of the organization and crossing of the data both in independent form, for each one of the programs, as well as when grouping them in global manner.

For the development of the study, there was the collaboration of the Group of Investigation of the Post-Graduate Program, Masters and Doctorate in Education of the PUCPR, directed by Professor Doctor Ana Maria Eyng. They contributed from the construction and validation of the forms and the collection of data in Brazil up to the laborious and intense phase of organization of the materials, digitalization of documents, writing and transcription of interviews. The $\mathrm{PhD}$ students that participated were Ricardo Lemes da Rosa, Janice Strivieri Souza Moreira, Auda Aparecida Ramos, Eduardo Felipe Hennerich; the master's students were Jéssica Adriane Pianezzola, Marina Ignez de Oliveira; and the holders of scholarships, of scientific initiation, Laís Rolim Simão, Bruna de Oliveira Silva Mosson and Angela Negrete Adriàzola. In addition for the transcription we had the collaboration of Doctor Marciele Stigler Ribas, graduate of the Group of Investigation, and in the writing of the responses, Ana Paula Feuser Eyng, Bachelor of Arts in Law, and Marilene Duarte, Bachelor of Arts in Pedagogy, collaborated. 


\section{ORGANIZATION AND HIGHLIGHTED ELEMENTS OF THE REPORT}

For the investigation of violence in the daily lives of boys, girls and adolescents, in the field study were considered three blocks of information collection: 1. Characterization of the consulted subjects; 2. Participation and dynamics in the programs; 3. Perceptions on rights and learning constructed from the participation in the program.

The information obtained allowed the identification of risk factors, which points out the necessary learning, so that the boys, girls and adolescents can develop protection resources before the violence that affects them in their daily contexts.

\subsection{VIOLENCE RISK FACTORS IN THE DAILY LIFE OF CHILDREN}

The eleven violence risk factors identified by the participants (boys, girls and adolescents, family members and teams) make evident the effects of the structural factors, of the logic of stigmatization and naturalization of poverty in the life of boys, girls and adolescents.

The risk factors presented here are described beginning from the conversations with the subjects and include problems related to the family, community, public policies, economy, education, culture, health, security, criminality, social-emotional dimension and violation of rights.

- Family: the abandonment, the lack of attention, the oppression toward boys and girls, the physical and psychological ill-treatment, the reproduction of environmental violence inside the house, the lack of parental tools for taking care of the boys and girls, the lack of communication, the drug consumption and unemployment. In the same way, the parents' and family's malfunctioning, the intrafamily violence among the adults and with the boys and girls, provokes the naturalization of verbal, physical and psychological ill-treatment. 
- Community: living together in very violent contexts naturalizes and reproduces violence and tends to promote criminal practices. Degraded community spaces, precarious dwellings, the lack of an infrastructure of cleaning up and drainage. The discrimination and exclusion of the population. Boys and girls living on the street who grow in violent surroundings and environments, where space and equipment for recreation, sports and leisure are lacking.

- Public Policies: lack of implementation of policies of integral protection for children. There is a deficit in the physical, material infrastructure, and in the availability of specialized professionals in the attention destined for boys, girls, adolescents and young people. It is observed that there is a fragile inter-sectorial articulation in the management of the public policies and in the public-private associations.

- Economy: poverty and extreme poverty, scarce resources, unemployment, informal work, economic exploitation, lack of opportunities and a significant social exclusion.

- Education: educational inequality, school abandonment, precarious education, lack of study for adults and young people. There is no possibility of having access to quality education. Little information and scarce knowledge. Illiteracy and disinformation.

- Culture: naturalization of violence, normalization of the abuses and ill-treatments. The Patriarchal culture (machismo) is evident in the gender violence, the vision centered on the adult (generational factor) and the patrimonial vision (boys and girls as property of which they can dispose). Discrimination, stigmatization and invisibility of the children.

- Health: high consumption of alcohol and drug addiction; wounds, hurts, and physical, psychological and emotional traumas caused by violence. Depression.

- Security: one cannot go out on the street feeling secure because of the risk of aggressions and physical or material harm or simply the threat of death. There is lack of vigilance and adequate control by the police. Uncontrolled criminality. 
- Criminality: high rate of thefts, assaults, kidnapping, shooting, and stray bullets. Delinquency, drug and arms traffic. Disputes among gangs and drug traffickers. Corruption.

- Socio-emotional: devalued self-concept and low expectations. Links or bonds with peers associated with criminality and the use of alcohol and drugs. Reproduction of behavior and violent actions as a factor of protection and subsistence. Delinquency.

- Violation of rights: Few opportunities to develop potentialities of the boys and girls, both in the family and in the community environment. Negligence, family carelessness, abuse, physical, verbal and psychological violence, and sexual violence. Correction by means of physical punishment, human traffic, ill-treatment of children. Use of boys and girls for children's labor and for stealing.

The overcoming and diminishment of these risk factors on children presupposes a rupture to the logics of stigmatization, responsibility and exclusion of poverty, by means of policies and programs capable of transforming the circumstances that produce them. Therefore, based on the diagnosis of the causes, structural policies are required that act in the prevention of the violation of rights and create conditions and opportunities for the effective protection and development of children.

The information obtained with the subjects as far as their characteristics are concerned, and the expectations that they have of their participation in the programs reveal aspects that make evident the risks of violence to which girls, boys and adolescents are daily subjected.

\subsection{CHARACTERIZATION OF THE CONSULTED SUBJECTS}

The configuration of the elements that characterize the subjects embraces aspects that affect their identity perception, including age, sex, ethnical belonging, religion, religious affiliation, knowledge on the family economic income, level of family income and schooling. These aspects were asked to all the participants. 
The boys, girls and adolescents were also asked on grade repetition and school abandonment, considering the repeated grade, and in case of abandonment, which were the reasons that motivated it. The family and relatives of the boys, girls and adolescents were also asked on their profession and work. The members of the team of the programs were asked on their profession and the function that they presently exercise.

The data or information collected in the characterization of the participants highlights the conditions of poverty and extreme poverty in which boys, girls and adolescents and their families live. This is evident by the type of labor activities of those who work; a significant percentage corresponds to informal or precarious work (without any guarantee). Regarding the relatives or family members, $27.7 \%$ is not working and of the $72.3 \%$ that works, the majority does it in poorly paid activities and/or informal ones.

Among the boys, girls and adolescents, of the $41.9 \%$ who say they have knowledge of the economic income of the family, $62.3 \%$ indicate that the family income is two to four minimum salaries; $20.8 \%$ affirm that it corresponds to one minimum salary; $9.4 \%$ say it is less than a salary, and $7.5 \%$ inform having an income of five to seven salaries.

Among the relatives or family members, $56.2 \%$ affirm that the family income is in the group of two to four minimum salaries; $22.5 \%$ indicates that it is of one salary; $14.6 \%$ indicate that the income is less than one salary a month. Only $6.7 \%$ have an income between five and seven minimum salaries and seem to have an income that permits them to take care of the basic needs of the family. Another indicator of low income is the $25 \%$ of families who receive economic help from the State.

The minimum salary of reference in 2017 in Brazil was 937 reais; in Mexico, 2.200 Mexican pesos; in Guatemala, 2.893 quetzales; in Chile, 240.000 Chilean pesos. Those values in the currency of each country correspond to the following amounts in US dollars: Brazil - US\$275, Mexico - US\$122; Guatemala - US\$ 390 and Chile - US\$ 401.

In reference to the schooling of family members or relatives, only 33.7\% finished High School, 7.6\% finished Graduation, and therefore, $58.7 \%$ did not complete school education, which includes Elementary and 
High School. Among these $18.5 \%$ did not complete elementary education and $3.3 \%$ are illiterate.

The low schooling rate of adults could be the result of school failure, early abandonment or the impossibility to attend school. This seems to perpetuate itself in the high rate of repetition and abandonment among boys, girls and adolescents.

The relation between the greater concentration of age groups of boys, girls and adolescents and the school year they are following makes it evident that there is a great age/grade distortion, which indicates difficulties and failure in studies. This awareness is strengthened by the fact that $40 \%$ of the participants informed that they had school failure and 30.2\% indicated they had abandoned school. Among the reasons indicated to justify school abandonment are found aspects that remit to the stigma of poverty that affects children.

School failure tends to perpetuate the circle of violence, which is nourished in the contexts of poverty. The violation of the right to education prevents the subject's advance, their possibility of a less violent present and of constructing a midterm or long-term Project in which injustices and privations that have affected their life are overcome. When initial formation is compromised, professional formation is also compromised, condemning them to unemployment, to underemployment, to economic exploitation and, in many cases, to illegal work.

\subsection{PARTICIPATION AND DYNAMICS IN THE PROGRAMS}

The information on participation of the subjects in the programs were obtained in the responses to the questions on time of permanence in the program, how did they know about the program, the criteria applied to enter the program, the expectation when entering it, the difficulties to frequent the program.

The motivations for participation in the programs, considering the criteria of inclusion and the expectations at the beginning, indicate a general scenario of violence (ill-treatment, abuses, criminal acts committed by 
adolescents) and the need to foresee and prevent the risk of suffering violence (to leave the street, not remain alone at home). It is a question of a scenario marked by poverty.

In the perception of the boys, girls and adolescents, their inclusion in the programs was granted due to three factors: 1 ) the need for protection, because they remain home alone, so they leave the street, so they leave drug consumption, because of intra-family violence, or sexual abuse, to guarantee basic needs, to seek security before risk, because of family abandonment, human traffic; 2) strengthening: participate in activities, change of attitude, studying; 3) responsibility: to fulfill a legal process. These attitudes are corroborated by the perceptions of the family members when indicating the reasons and criteria of inclusion of boys, girls and adolescents in the programs.

The difficulties to participate, identified by $34.4 \%$ of the participating boys, girls and adolescents and by $36 \%$ of the family members, are indicative of the socio-economic difficulties. For example, not having resources for transportation, not having security to displace oneself in the environment or having to work. The participants of the teams confirm those limitations, indicating the difficulties to carry on with the program; they also add the scarcity of resources, the lack of external alliances, the insufficient time of permanence and destined to work with the boys, girls and adolescents. All these aspects show the contours of the context of poverty, in which those boys, girls and adolescents grow.

The purposes that the boys, girls and adolescents have to participate in the programs emphasize the participation, protection, the learning of new things, communication, respect, improving in living together, improving self-esteem, the transformation of the community. A whole series of things to learn is considered to affect the individual and collective strengthening of capacities and skills of boys, girls, adolescents and their family members.

The family members also indicate as purpose of the activities the possibility of improving the quality of life, citizenship and the hope of a better future. Nevertheless, it is also quite strong what refers to the change of behavior and the attitudes of the boys and girls. This expresses an erroneous understanding of the dynamics of violence, which affects them. That is, the 
perceptions show clearly the belief that girls themselves occasioned the abuses and ill-treatment suffered by them. In this way, the victims become responsible for the violence that they suffered and continue to suffer.

The members of the teams indicate as purpose of their work in the programs, to give and develop, in boys, girls and adolescents: voice, opportunity to participate, learning, living together, strengthening of citizenship, autonomy, leadership, control of impulses, protection in the face of risks, study, information, learning of trades, strengthening of selfesteem and education in human rights.

The information of the participants, regarding the respected rights, benefits acquired and learning constructed in the programs, give evidence of the importance of constituting resources of protection that can be applied in the family, community and school daily life.

\subsection{RIGHTS AND THEIR GUARANTEE IN THE PROGRAMS}

In this section, information related to the learning developed in the programs with the rights of girls, boys and adolescents was investigated. The first two questions were: What do you understand by human rights? What do you consider is a fundamental right for all persons? Then a list was presented to them with all the rights considered in the Convention on the Rights of the Child (ONU, 1989), asking that they indicate which are the most fundamental rights for the life of the boys, girls and adolescents. In the fourth question it was found out whether the participation in the program contributes to guarantee some of the rights of the Convention and, in case they said yes, to say of which of them.

In explaining what they understand by human rights, a significant percentage of participants used examples of rights as a definition; this made us turn the presentation of those responses into a new one. Among the rights quoted by the boys, girls and adolescents the most valued ones were the following, according to the order of importance: education (16.5\%), freedom (13.4\%), dwelling (11.3\%), nourishment (9,2\%), respect (8.2\%), and health (7.2\%). On their part, the family members emphasized more the following 
rights: respect (25.9\%), freedom to come and go (24.1\%), and education (13.8\%). There was a significant number of family members that did not know how to answer. Besides, responses were collected indicating that rights do not exist, since there is much injustice, that human rights are not correct, that they are destined to defend persons who commit errors.

Regarding the members of the teams, the types of rights quoted the most are education (24.5\%), health (14.1\%), life (14.1\%) and nourishment (11\%).

In the second question, on which is the most fundamental right, the responses of the boys, girls and adolescents point out the right to education as the primordial one for all persons with $17.1 \%$. Then, they say respect with $12.2 \%$, family with $9.8 \%$, to be free with $7.9 \%$ and freedom of expression with $7.3 \%$. Family members indicated as the most fundamental right, respect with $17.5 \%$, followed by education with $14 \%$. The members of the teams pointed out: dignified life, education and health with $26.8 \%, 9.6 \%$ and $8.1 \%$, respectively.

Regarding the questions considered in the Convention which they considered a priority for their lives at present, boys, girls and adolescents indicated as the most important ones: health (12.2\%), education (11.8\%), and life (11.2\%). Family members pointed out as fundamental for the life of their children at that moment: health (11\%), protection against all types of violence (11\%), education (11\%), and life (10.2\%) The members of the teams indicate: life (17.6\%), education (17.6\%) and protection against all types of violence (13.7\%).

When asked if participation in the program contributes to guarantee the rights which are in the Convention, and which of those, the boys, girls and adolescents pointed out: education with (18.2\%), freedom of opinion and expression with $11.4 \%$, health with $9.3 \%$, culture with $7.3 \%$, sports and recreation with $7.1 \%$ and protection against all forms of violence with $7.1 \%$. All the family members affirmed that the participation in the programs contributes to guarantee the rights and indicated those more guaranteed were health with $12.1 \%$, education with $12.1 \%$ and social reinsertion with 
$12.1 \%$. In the same way, all the members of the teams pointed out that the programs contribute to guarantee these, mentioning in the following order: orientation in and for human rights (15.8\%), freedom of opinion and expression (13.2\%), culture (19.5\%) and education (10.5\%).

\subsection{LEARNING BUILT IN THE PROGRAMS}

In this section we will probe the perceptions that the participants have concerning the difficulties that are overcome, the benefits and the learning which have made possible for the boys, girls and adolescents the acquisition of protection resources to contribute in the daily life of their families, communities and schools.

The information contributed by the boys, girls and adolescents and the interviewed family members was obtained as a response to the following questions: Which are the difficulties the boys, girls and adolescents overcame by participating in the program? Which were the benefits generated for the life of the boys, girls and adolescents, beginning with the participation in the program? Which has been the learning constructed in the program and in which way does this learning contribute for the daily life of the boys, girls and adolescents in their families, communities and schools?

To those forming the teams it was asked: Which are the positive points that you identify in the program? Which is the learning that the program offers to the boys, girls and adolescents? Which are the contributions of that learning for the daily contexts of the boys, girls and adolescents in their families, communities and schools?

As a total number, we identified 20 overcome difficulties in the perceptions of the boys, girls and adolescents, from their participation in the programs. Among these, they mention, in the first place, timidity and shyness; in the second place, the development of self-control, behavior and attitudes: in the third place, living together, conversation and communication; and in the fourth place, physical activity and improvement in health. 
The improvements identified by the boys, girls and adolescents are corroborated by the 27 benefits they perceive were proportioned by their participation in the programs. In the first place, they mention the improvement in living together and in communication. In the second place, they indicate four benefits with the same level of consensus: improvement in emotional control, change of perspective in thinking about life, improvement in school and valuing study, development of respect and empathy. In third place, they place improvement in health and in the artistic and corporal skills.

In the perspectives of the family members 22 difficulties overcome by the boys, girls and adolescents were identified. In first place, they mention living together, conversation, communication; in second place, self-control, behavior, attitudes; in third place, overcoming timidity, shyness; in fourth place, socialization and integration; and lastly, self-esteem. The family members also point out 27 benefits proportioned by the programs to the boys, girls and adolescents, pointing out in first place improvement in emotional control, behavior; then emotional improvement, wellbeing, joy; in third place, improvement in living together, communication and improvement in school, valuing the study.

As for the benefits of the programs, according to the perceptions of the participants from the teams, it's emphasized in all the programs that the work has a focus on human rights, from the formation in and for the human rights, in both the guarantee and the restitution of human rights. Another emphasized aspect was the importance of the work integrating the family, valuing participation, expression and autonomy of the participating boys, girls and adolescents. The points emphasized by the members of the teams corroborate the perceptions of the boys, girls and adolescents and of the family members, regarding the overcome difficulties and the benefits that the participation in the programs has offered them.

The difficulties overcome, the benefits acquired, and the positive points identified in the programs, result from the constructed learning beginning from the inclusion and participation in their dynamics. However, in order to deepen the information on the contribution of the learning, we asked the participants to relate them with the daily contexts of the children and adolescents in their families, communities and schools. 
The contribution of the learning emphasized by the boys, girls and adolescents for their family relationships has to do with the strengthening of respect, communication and closer living together, with mutual support along the family members. Those resources when developed also contribute in the relationships in daily living together with their communities. The boys, girls and adolescents emphasize from their learning, the improvement of sociability, of respect and of the capacity to identify and avoid risk factors. Concerning the contribution for daily life at the school, the boys, girls and adolescents reaffirm the learning of respect and of living together. The valuing of studies and the academic improvement are also indicated, as is the expectation of the contribution of education to their life project.

Concerning the learning for the daily contexts of the boys, girls and adolescents, the family members presented as contributions for daily family life: communication, respect, participation, dialogue, behavior, good manners, obedience, discipline, organization. For the daily life of the boys, girls and adolescents in the community are emphasized: solidarity, respect, no discrimination, communication, better relationship with persons, having good friends, value and care of the community space. Concerning the contributions for school life: respect, responsibility, dedication, and discipline, and participation, improvement in achievement, motivation and interest, to continue studying.

In the responses of the participants of the programs' teams on the contributions of the learning regarding the family, the following are emphasized: living together, relationship, respect communication, mutual help among the members of the family, identification of violence, to know and to demand or claim the rights. The contributions for the daily contexts in the community are living together, respect, sharing knowledge, being a point of reference, leadership, looking at the community better, identify and separate oneself from risks such as drugs. The principal contributions for performance in the school are: participation, relationships, respect, behavior, to continue advancing in the studies, understanding of education as a human right, strengthening of the identity, academic improvement. 


\subsection{FACTORS OF PROTECTION IN CHILDREN'S DAILY CONTEXTS}

The information obtained in the study, in the perceptions of the participants regarding the benefits and the constructed learning from participating in the programs, are indicative of factors of protection capable of strengthening the boys, girls and adolescents to guarantee their rights in the daily spaces.

The whole series of learning, quite important, responds to the expectations and the objectives proposed by the programs. Nevertheless, the learning needs to be strengthened and consolidated; making it possible that it becomes permanent resources of protection and guarantee of rights.

In that perspective, efforts are demanded and required so that the policies and programs can, in fact, contribute in the learning of protection resources, guaranteeing the rights of the boys and girls.

We identify eleven factors of protection, described in conformity with the responses of the subjects consulted. These embrace resources related to the family, community, public policies, economy, education, culture, health, security, justice, socio-emotional aspects and guarantee of rights.

- Family. Dialogue: to talk, have greater freedom of expression and communication at home, listen, respect. Care: to become responsible, accompany, give attention to the children, be home for a longer time, supervision of an adult, integral care. Affection: give love, support, strengthen the bonds. Education: orientation, to strengthen the values. Preparation: sensitiveness and capacity of the parents to assume their role, creating new forms of relationships with the children.

- Community. To raise awareness in the population, be in solidarity and participate, help, for example, to avoid that the boys and girls are out on the street. To maintain the public spaces for recreation, leisure time, and outside activities for the boys, girls and adolescents. Actions and programs in network.

- Public Policies. Strengthening of the public system with intersectorial articulation and public-private associations of work in 
networks for the attention and protection of children. Policies that include all children focusing on the protection of gender and the guarantee of the human rights. Create public spaces, institutions and programs that have teams and equipment for activities of protection, recreation and leisure for boys and girls. Access to basic services as a right. Programs of psychological attention. Programs to deal with the dependence on alcohol and drugs.

- Economy. More opportunities for work, employment, more dignified salaries, more economic access to take care of basic needs. Eliminate children's work.

- Education. Education and schooling represent protecting factors. Schools in different areas, being informed, sexual education, education in human rights. More education, technical schools, access to professional formation. Change the form of educating.

- Culture. Promote culture, orientation for the change of mentality, denaturalize violence, overcome oppression and discrimination of gender and of children. Change the way of correcting boys and girls, doing it with respect and dialogue. Understand and treat boys and girls as subjects of rights.

- Health. Free psychological therapies in health centers, psychoeducation, individual and family psychological help. Treatment for alcohol dependence and drug addiction.

- Security. Greater security, being able to count on the police, more vigilance, rounds and night watch by police. Do not leave the boys and girls alone, especially on the street. Control and fighting against criminality.

- Justice. Justice more accessible to complaints, having the habit of denouncing. Justice system, respect the laws. Sanction the abusers and the traffickers. Combat the drug traffic, kidnapping, traffic and abuse of boys, girls and adolescents.

- Socio-emotional. Positive self-esteem through the strengthening of bonds, in all spaces. Development of protection strategies by the individual in trustworthy spaces, in the family, school and 
community. Change of thought, attitudes, and behaviors, selfcare. Empowerment and leadership.

- Guarantee of rights. Protection through programs and social actions, including family and community spaces guaranteeing of the rights of children. Include all sectors for the prevention of the family, guaranteeing education, health, culture, sports, art, recreation/leisure, security, training for work and guidance in and for human rights.

The protection factors in the guarantee of rights can derive in policies and programs that promote a broad dialogue including the children's groups. The guarantee of being listened to, of participation in the Decisions, which affect them, guarantees the right to the conditions of integral development and to progressive autonomy.

The work developed in the investigated programs stresses the importance of affective fostering, the need for support and psychological orientation to the boys, girls and adolescents and to their families, the strengthening of self-knowledge, in general, and the need of juridical and material support (protection, nourishment, shelter) in specific cases.

The results stress the challenge to extend the actions of prevention to reach a larger number of boys, girls and adolescents. It also stresses the need for support and protection in sufficient time so they are capable of overcoming the stigma to which they are subject, develop and apply by themselves the protection resources, and in this way construct better possibilities in their life paths, with access to education and professionalization.

\section{MAIN CONCLUSIONS}

The struggle for the guarantee of the rights of children, after three decades of the agreements reached in 1989 with the Convention of the Rights of the Child, is still far from conclusion. On the contrary, new efforts are necessary every day. 
It is vital, then, to maintain vigilance in favor of the defense of children, strengthening structural State policies and programs destined to the children, which are vectors of transformation of the conditions of existence of boys and girls, favoring inclusion and equity.

Shared intentionality in the recognition and effective participation of boys, girls and adolescents as subjects of rights presupposes the constitution and strengthening of:

- Policies and programs which will act in the preventing violence and, consequently in the individual and collective strengthening.

- Structural State policies, which will act in inter-sectorial ways, with the focus on the generational impact, from midterm to long term, affecting the genesis, the causes of the violence risk factors, diminishing and overcoming them.

- Participation and leadership of boys, girls and adolescents in the effective exercise of rights to free expression and to gradual selfregulation.

- Programs of prevention and protection in network, with joint acting of the Governmental field and of civil society, for global attention to the needs of development of protection resources for children and strengthening of their wellbeing.

- Communities and groups of practices and support to the boys and girls in their daily spaces. By means of workshops, sport practices and recreation, psychotherapies and artistic activities, allow their individual development and the living together with their peers and significant adults.

- Educational and psycho-therapeutic orientations that stimulate the constitution of positive and resilient identities, strengthening selfrespect, valuing of self and one's potentialities, and of a self-esteem based on knowledge of oneself that is well-structured.

- Knowledge and appreciation of diversity, having as reference against hegemonies epistemologies, capable of promoting the raising of public awareness, the dialogue among the different 
cultural knowledges, the interaction between ethnic groups, races, gender, religions and generations.

- Constitution and exercise of social justice that acts in the spheres of redistribution, recognition and representation, in the guarantee of the rights of children and of conditions of development for each boy and girl.

The expectation of the construction of those factors of protection of children and of the strengthening of each boy and girl as a subject of rights requires new learning, preceded by the deconstruction of concepts and practices quite internalized in children's daily spaces. It implies, therefore, to unlearn violence, discrimination, lack of respect, assistance, blaming of the victim, subordination and disqualifying of the child. Therefore, it consequently requires learning new individual and collective strategies, which allow children to go back to their life projects for a less unjust present and for a future of greater equity.

In this sense, the guarantee of rights, countersigned in the studies of Fraser (2006, 2007, 2008, 2009), presupposes a redistribution that seeks a more just allocation of resources and goods, the recognition of the differences that constitute diversity, under the most varied aspects, (gender, generation, ethnic groups, nationality, sexuality, etc.) and the political representation, which requires social agreements to allow all to participate in social life. Therefore, to overcome inequality and exclusion expressed in injustices means to overcome institutionalized obstacles which prevent many subjects to participate "[...] in conditions of equality with others, as integral associates of social interaction” (FRASER, 2008, p. 5).

\section{REFERENCES}

FRASER, N. Da redistribuição ao reconhecimento? Dilemas da justiça numa era “pós-socialista”. Cadernos de Campo, v. 15, n. 14/15, p. 231-239, 2006.

FRASER, N. Mapeando a imaginação: da redistribuição ao reconhecimento e à representação. Estudos Feministas, v. 15, n. 2, p. 291-308, 2007. 
FRASER, N. Escalas de justicia. Barcelona: Herder, 2008.

FRASER, N. Reenquadrando a justiça em um mundo globalizado. Lua Nova, n. 77, p. 11-39, 2009.

UNITED NATIONS (UN). International Convention on the Rights of the Child. Adopted by the Resolution 44/25 of the General Assembly of the UN. November 20, 1989. Entered into force in September 2, 1990, in conformity with article 49.

UNITED NATIONS (UN). World Report on violence against children (A/61/299): Report of the independent expert for the study of violence against children of the UN. General Assembly of the United Nations, August 29, 2006.

SARMENTO, M. J. Pobreza infantil: factos, intepretações e desafios políticos. In: SARMENTO, M. J.; VEIGA, F. (Orgs.). Pobreza infantil: realidade, desafios, propostas. Porto: Húmus, 2010. p. 179-191. 
Organização dos Estados Americanos Mais direitos para mais pessoas
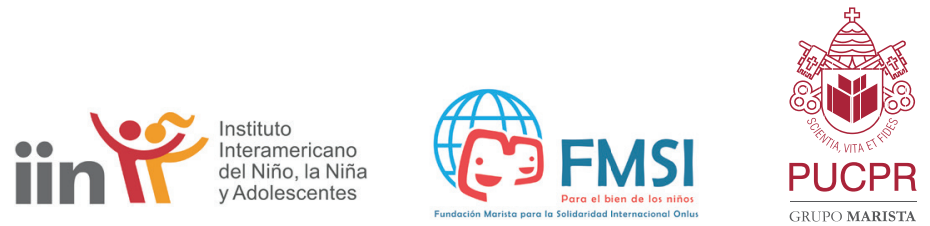

$111 /$ observatório

(O) das Juventudes 